\title{
A relação entre economia e natureza no capitalismo: uma discussão a partir da urbanização da cidade de Macaé-RJ.
}

The relationship between economy and nature in capitalism: a discussion based on the urbanization of the city of Macaé-RJ.

La relation entre économie et nature dans le capitalisme: une discussion basée sur l'urbanisation de la ville de Macaé-RJ.

La relación entre economía y naturaleza en el capitalismo: una discusión basada en la urbanización de la ciudad de Macaé-RJ.

\section{Oséias Teixeira da Silva}

\section{(2) OpenEdition}

\section{Journals}

\section{Edição electrónica}

URL: http://journals.openedition.org/espacoeconomia/17338

DOI: 10.4000/espacoeconomia.17338

ISSN: 2317-7837

\section{Editora}

Núcleo de Pesquisa Espaço \& Economia

\section{Refêrencia eletrónica}

Oséias Teixeira da Silva, «A relação entre economia e natureza no capitalismo: uma discussão a partir da urbanização da cidade de Macaé-RJ.», Espaço e Economia [Online], 20 | 2020, posto online no dia 26 novembro 2020, consultado o 29 janeiro 2021. URL: http://journals.openedition.org/espacoeconomia/ 17338 ; DOI: https://doi.org/10.4000/espacoeconomia.17338

Este documento foi criado de forma automática no dia 29 janeiro 2021.

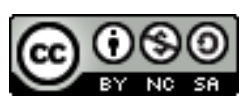

Espaço e Economia - Revista brasileira de geografia econômica est mise à disposition selon les termes de la licence Creative Commons Attribution - Pas d'Utilisation Commerciale - Partage dans les Mêmes Conditions 4.0 International. 


\section{A relação entre economia e natureza no capitalismo: uma discussão a partir da urbanização da cidade de Macaé-RJ.}

The relationship between economy and nature in capitalism: a discussion based on the urbanization of the city of Macaé-RJ.

La relation entre économie et nature dans le capitalisme: une discussion basée sur l'urbanisation de la ville de Macaé-RJ. La relación entre economía y naturaleza en el capitalismo: una discusión basada en la urbanización de la ciudad de Macaé-RJ.

\section{Oséias Teixeira da Silva}

\section{Introdução}

1 A ascensão do capitalismo como sistema a regular as relações metabólicas da sociedade e da natureza impõem intensas transformações ao meio ambiente. Embora a consciência e a discussão política sobre esses assuntos sejam relativamente recentes sendo que a maioria dos debates internacionais sobre o meio ambiente tem sua origem na década de 1970, os efeitos da ação capitalista sobre o meio ambiente e seu caráter devastador tem sido notado há muito mais tempo. 0 presente trabalho buscará trazer elementos para a compreensão dessa questão a partir da discussão teórica e também de um trabalho empírico sobre as transformações ambientais advindas da urbanização na cidade de Macaé - RJ. Mais que um estudo de caso o que buscamos é analisar como o referencial teórico utilizado pode auxiliar na compreensão do processo de urbanização acelerado da cidade de Macaé.

2 Na primeira parte do trabalho realizamos uma discussão geral sobre a relação entre economia e natureza no capitalismo, salientando a contribuição de (POLANYI, 2012) 
para essa discussão. Na obra citada, o autor aponta o caráter destrutivo das relações regidas pelos mercados autorregulados, especialmente em relação aquilo que ele denomina mercadorias fictícias, ou seja, elementos que embora não sejam produzidos pelo capital, pelo fato de vivermos em uma sociedade de mercado precisam ser transformadas em mercadorias e organizadas em mercados específicos. Essas mercadorias fictícias são: a terra que seria apenas outro nome para a natureza, o trabalho e o dinheiro.

3 A terra consiste em um bem fictício justamente pelo fato de que não é produzida pelo trabalho não sendo um bem econômico como outros bens industriais. No entanto, para que uma economia de mercado funcione é preciso que todos os fatores produtivos estejam disponíveis no mercado. Assim pelo instituto da propriedade privada a natureza é transformada em mercadoria podendo ser apropriada privadamente e comprada e vendida como se fosse um bem industrial. o caráter artificial da mercadoria natureza está tanto no fato de que ela não é produto do trabalho humano quanto no fato de que toda parcela de natureza é irreprodutíveis sendo suas características únicas em cada fração da natureza.

4 Ainda na primeira parte do trabalho, apontamos a partir de diferentes autores aspectos contraditórios da relação entre natureza e economia capitalista. (HINKELLAMERT, 2007) aponta que a relação do capital com a natureza se baseia no princípio da tortura, ou seja, o capital busca a eficiência que se materializa com a maior taxa de lucro possível ignorando todas as conseqüências do processo produtivo. De forma geral, o que se busca é a eficiência, o lucro e ele devem ser buscados acima de todas as considerações morais e éticas. Especialmente na relação com natureza o princípio da tortura é muito importante, afinal produzir no capitalismo é em grande parte torturar a natureza para que ela gere o máximo de lucro possível.

5 Avançando na discussão da relação entre economia e natureza, apontamos como a incontrolabilidade do sistema do capital colocada por (MÉSZÁROS, 2011) coloca a impossibilidade da resolução completa da questão ambiental, apenas de sua regulação como se dá a partir da legislação ambiental. A incontrolabilidade significa que o capitalismo é um sistema que embora composto por unidades racionais tenha um movimento conjunto, sistêmico que é irracional e incontrolável. Tal discussão é o desenvolvimento do conceito de anarquia da produção capitalista presente em (MARX, 2011). A incontrolabilidade em relação à natureza se coloca no fato de que todos os capitalistas individuais são compelidos a reduzir os custos ambientais na produção e externalizá-los para a sociedade, o que implica muitas vezes a necessidade de empresas poluentes se transferirem para países menos desenvolvidos e que possuem legislações ambientais menos rigorosas.

6 A partir da discussão realizada na primeira parte do trabalho buscamos analisar a evolução urbana de Macaé, cidade do interior do Estado do Rio de Janeiro, a partir da década de 1970, a luz da perspectiva ambiental. Essa data foi escolhida, pois temos como marco nessa década a instalação da Petrobras e de um conjunto de empresas do ramo offshore na cidade, que levam a um intenso crescimento demográfico e urbano (PAGANOTO, 2008). De forma geral, discutimos que esse crescimento urbano se dá tencionado pela existência de duas das três grandes unidades da Petrobras na cidade e que se irão se instalar em áreas fora da área urbana consolidada até então: o Terminal Parque de Tubos e o Terminal Cabiúnas. Ainda colocamos que do ponto de vista ambiental o crescimento urbano da cidade se deu a partir do contínuo aterramento de 
áreas de brejo ou de manguezal que passaram a constituir novos bairros na cidade. Essa enorme expansão urbana se permitiu por um lado uma grande acumulação de capital no setor de produção imobiliária teve como conseqüência direta um enorme crescimento do fenômeno das enchentes na cidade, uma vez que boa parte das áreas que antes serviam para o armazenamento das águas em época de cheias passou a ser urbanizadas e impermeabilizadas, dificultando o fenômeno da infiltração, favorecendo o escoamento superficial e a intensificação das enchentes.

7 Por outro lado a expansão espacial da cidade também revela a lógica da tortura, uma vez que esse crescimento se dá em grande parte a partir de uma ampla devastação de ecossistemas naturais, especialmente áreas de brejo ou de mangue que aterradas passam a fazer parte da lógica de expansão imobiliária e acumulação de capital no setor imobiliário. Assim é somente a partir de sua devastação que a natureza se insere como elemento da urbanização na cidade, mesmo que a devastação da natureza, muitas vezes implique na produção de uma natureza artificializada em um momento posterior. Assim a natureza só existe para a expansão urbana da cidade como objeto de tortura, como natureza que está lá para ser devastada, queimada, aterrada e urbanizada até que, por fim, não haja vestígios das formas de natureza anteriores.

\section{Natureza e capitalismo: a privatização da natureza e a incontrolabilidade do capital do ponto de vista do meio ambiente}

8 Em uma sociedade capitalista tendemos a naturalizar a mercantilização das coisas sem pensar no seu significado mais profundo e nas conseqüências sistêmicas disso. Assim a mercantilização do trabalho implica na mercantilização do homem que é seu portador, o que pode levar a uma intensificação da exploração do trabalho e a degradação da condição humana, a mercantilização do dinheiro implica na expansão desenfreada do mesmo que pode levar a crises financeiras enquanto a mercantilização da natureza pode levar a exploração desenfreada da mesma tendo como consequência a degradação ambiental. Porém precisamos começar pelo motivo pelo qual o capitalismo necessita mercantilizar a natureza, condicionando seu acesso através do monopólio da propriedade privada. Segundo (POLANYI (2012, p 43)

Uma vez que as máquinas complicadas são dispendiosas, elas só são rentáveis quando produzem uma grande quantidade de mercadorias. Elas só podem trabalhar sem prejuízo se a saída de mercadorias é razoavelmente garantida e se a produção não precisar ser interrompida por falta de matérias primas necessárias para alimentar as máquinas. Para o mercador isto significa que todos os fatores envolvidos têm de estar à venda, i.e., eles precisam estar disponíveis, nas quantidades necessárias, para quem quer que esteja em condições de pagar por eles.

9 Segundo o raciocínio do autor as raízes da mercantilização da terra, do trabalho e do dinheiro estão no surgimento do sistema fabril. Ao ampliar a escala de produção e o volume do capital investido a grande indústria surgida com a I Revolução Industrial gera a necessidade de um fluxo constante de fatores produtivos, ou seja, todos os fatores produtivos precisam estar continuamente disponíveis para aquisição. Em uma sociedade mercantil a única forma de se garantir um fluxo contínuo de fatores produtivos é criando mercados de todos esses fatores. Não importa se esses fatores são produtos produzidos como mercadorias, ou elementos que anteriormente não eram mercantilizáveis e passam então a serem. Esse é justamente o caso do acesso à natureza. Não que inexistissem anteriormente formas de apropriação privada da natureza, mas a 
industrialização gera um grande impulso a mercantilização e apropriação privada da natureza que antes era comum. Um caso bastante conhecido disso é o cercamento das áreas comuns na Inglaterra, fato descrito por (MARX, 2011).

10 A transformação da natureza em mercadoria só pode se dar a partir da sua apropriação privada, uma vez que a terra é fatiada e vendida em parcelas, terrenos. Cada terreno dá ao seu proprietário direito praticamente exclusivo a natureza que está na superfície desse terreno. Assim a transformação da natureza, depende da apropriação privada da terra, que por sua vez só pode ocorrer pelo seu parcelamento. Só a partir da apropriação privada via parcelamento a natureza, ou melhor, os recursos que ela pode oferecer ao processo de acumulação de capital estarão disponíveis no mercado de forma contínua de modo a permitir a produção industrial em larga escala. Assim a compra e a venda da terra já devidamente parcelada em terrenos é a condição para que a natureza possa ser comprada ou vendida. Na verdade, do ponto de vista do capital não se trata da compra da natureza em si, mas da compra dos recursos naturais que existem no interior de uma parcela de terra.

11 Importante colocar que o autor compreende o capitalismo a partir do momento da da ascensão do taylorismo/fordismo, sendo que no momento atual teríamos outros determinantes para a organização produtiva. No entanto, a sua concepção sobre privatização da natureza, acreditamos, permanece válida atualmente. A privatização da natureza e de seu acesso como condição fundamental para a existência do capitalismo é apenas um aspecto dessa questão. Além de pensar na privatização da natureza temos que discutir a forma como o sistema capitalista se relaciona com ela. Nesse sentido (HINKELAMMERT, 2007, p 153) propõe que a relação do sistema capitalista com a natureza segue o que ele denomina lógica da tortura. Sobre a ideia de tortura o autor aponta o seguinte:

o general francês Massis dizia durante a guerra da Argélia: a tortura é eficaz; por conseguinte, é necessária. Do eficaz passa-se a afirmação da necessidade. Entretanto, a eficácia implica passar ao limite. A tortura somente é eficaz se leva o torturado até o limite do suportável. E como quando fazemos a prova de um material. Leva-se o objeto ao limite antes que se quebre (Materialzerreißprobe). Não obstante, o problema deste limite, e que não se pode conhecer ex ante. Quando o material é quebrado sabe-se que seu limite foi ultrapassado, ou seja, ex post. No caso do material sabe-se então ate onde ele aguenta. No caso do torturador é diferente. Muitas vezes passa o limite. Porem, então o torturado está morto. A eficácia, entretanto, necessita deste conceito de limite, levar a prova até o limite.

12 A questão central aqui é que na tortura o que importa é a eficiência, ou seja, os fins a serem obtidos, sendo que os meios para isso pouco interessa. Então, aquilo que é tornado objeto se torna algo a ser explorado até o limite para se atingir esse objetivo, mesmo que esse limite só seja conhecido após o objeto se romper ou ser destruído. 0 autor argumenta que a relação do capitalismo se dá justamente a partir daquilo que ele denomina princípio ou lógica da tortura. A natureza é vista apenas como um recurso a disposição do processo de acumulação, que pode e deve ser explorada ao máximo para se obter o máximo de lucro possível. A única questão aqui é o da eficiência, ou seja, da melhor ou da mais lucrativa forma de explorar a natureza. Segundo (HINKELAMMERT, 2007, p 161), deste modo o grande inquisidor espanhol Torquemada se dirigiu a Bacon enquanto:

(...) fazia-se a seguinte pergunta: É lícito não torturar um herege? Sua pergunta era negativa. Não perguntava se era lícito torturar o herege, mas sim se era lícito não o torturar. 0 mesmo dava a resposta: não é lícito não o torturar, porque desta 
maneira lhe roubaríamos a última oportunidade para salvar sua alma eterna. 0 herege tinha o direito irrenunciável de ser torturado. Bacon unicamente secularizou esta posição pondo no lugar da alma eterna do herege o progresso técnico infinito. Desta maneira faz se visível o fato de que a Inquisição foi a revolução cultural da qual nasceu a modernidade.

13 Portanto aquilo que denominamos como princípio da tortura, ou lógica da tortura surge com a inquisição, é secularizada e transplantada para a ciência moderna, e então se torna a base de toda atividade capitalista e da modernidade capitalista. 0 princípio básico é que a tortura longe de ser um ato desumano e cruel é pelo contrário um ato lícito e humanizador. Assim como o cristão, dotado de uma religiosidade superior tem o dever de torturar o herege para salvar sua alma, o capitalista tem o dever de torturar a natureza e os povos ditos "inferiores" para obter o desenvolvimento para eles.

$14 \mathrm{Na}$ inquisição, na ciência e no capitalismo a lógica da tortura tem uma estrutura discursiva bem parecida. Na inquisição se trata de torturar o herege para levá-lo ao conhecimento de Deus e, portanto a salvação da sua alma. Aqui se encontra uma idéia básica da lógica da tortura, a idéia de que os fins justificam os meios, ou seja, mesmo que seja preciso destruir o corpo e a vida do sujeito herético, tudo valerá à pena se conseguirmos salvar sua alma. O capitalismo de forma geral é permeado por essa idéia de que é sempre preciso um grande sacrifício para se obter um bem maior, veja, por exemplo, as cruéis políticas de austeridade, que muitas vezes levam a morte dezenas de milhares de pessoas tudo em nome de um crescimento econômico que resolverá todos os problemas do país e que normalmente nunca vem. Interessante também o fato de que a Inquisição representa uma completa ruptura com a noção mais tradicional de conversão, que é sempre um ato voluntário, resultado de um genuíno encontro com Deus. Aqui se trata de impor a força à conversão mesmo que usando a violência se necessário.

15 Bacon opera uma secularização do princípio da tortura e o torna a base da constituição da ciência moderna. Um laboratório pode ser visto de certa forma e dependendo da forma como é utilizado, como um local de tortura. Quando um animal é injetado com uma droga experimental isso obviamente pode levar a muita dor e mesmo a morte do animal mais tudo que importa é o resultado, ou seja, saber se a droga funciona. Assim a efetividade é alçada ao patamar de elemento mais importante do processo científico sendo que considerações de ordem moral e ética são muitas vezes descartadas.

16 Segundo o autor essa lógica da tortura também está presente nas atividades capitalistas, sendo a Inquisição segundo ele a revolução cultural que deu origem a modernidade capitalista. Toda atividade capitalista implica em uma lógica de tortura, em que o que se busca é a eficiência, ou seja, o maior lucro possível independente dos efeitos sociais ou ambientais gerados pelas atividades que dão origem a esse lucro. Assim as pessoas e a natureza são lançadas no moinho satânico (POLANYI, 2012) do capital para gerar o máximo de lucro sendo que o processo de produção capitalista podendo ser visto, da mesma forma que a Inquisição, como um processo sistemático de tortura, em que a Natureza é muitas vezes destroçada para dar origem a recursos naturais que alimentam o crescimento capitalista. A mineração é um exemplo eloquente de como a produção de recursos naturais implica em ampla e sistemática tortura e devastação ambiental.

17 Alguns conceitos trabalhados pelas ciências ambientais apontam claramente para a prática da tortura na relação entre sociedade capitalista e a natureza. É o caso dos 
conceitos de estresse antropogênico, que representa o estresse causado em plantas, por atividades humanas que levam a modificações nas condições do habitat das plantas que pode ocorrer pela elevação de ruídos, lançamento de esgotos, emissão de poluentes atmosféricos,etc. $\mathrm{O}$ conceito de impacto ambiental também indica a consequência de uma atividade humana que causa uma alteração, que pode ser maior ou menor, no funcionamento de um ecossistema natural. $O$ conceito de resiliência indica justamente a capacidade de um ecossistema de suportar um impacto sem alterar suas condições básicas de funcionamento. Todos esses conceitos indicam uma relação de tortura entre a sociedade e a natureza, em que as atividades humanas causam graves desequilíbrios ao metabolismo dos ecossistemas podendo causar inclusive a ruptura e a total degradação dos mesmos.

18 Por outro lado, (MÉSZÁROS, 2011) aponta para outro aspecto fundamental para a compreensão da relação entre capitalismo e natureza ao abordar a incontrolabilidade do sistema do capital. Segundo (MÉSZÁROS, 2011, p 96):

Antes de mais nada, é necessário insistir que o capital não é simplesmente uma "entidade material" - também não é, como veremos na Parte III, um "mecanismo" racionalmente controlável, como querem fazer crer os apologistas do supostamente neutro "mecanismo de mercado" (a ser alegremente abraçado pelo "socialismo de mercado") - mas é, em última análise, uma forma incontrolável de controle sociometabólico. A razão principal por que este sistema forçosamente escapa a um significativo grau de controle humano é precisamente o fato de ter, ele próprio, surgido no curso da história como uma poderosa - na verdade, até o presente, de longe a mais poderosa - estrutura "totalizadora" de controle à qual tudo o mais, inclusive seres humanos, deve se ajustar, e assim provar sua "viabilidade produtiva", ou perecer, caso não consiga se adaptar. Não se pode imaginar um sistema de controle mais inexoravelmente absorvente - e, neste importante sentido, "totalitário" - do que o sistema do capital globalmente dominante, que sujeita cegamente aos mesmos imperativos a questão da saúde e a do comércio, a educação e a agricultura, a arte e a indústria manufatureira, que implacavelmente sobrepõe a tudo seus próprios critérios de viabilidade, desde as menores unidades de seu "microcosmo" até as mais gigantescas empresas transnacionais, desde as mais íntimas relações pessoais aos mais complexos processos de tomada de decisão dos vastos monopólios industriais, sempre a favor dos fortes e contra os fracos.

19 O sistema do capital é incontrolável, justamente por ser um sistema totalizante que submete todas as esferas da vida humana a seu controle. A história do capitalismo pode muito bem ser descrita como a história de como cada recôndito da vida social passa a estar sob os ditames do processo de acumulação de capital. Inicialmente restrito a esfera das trocas e da produção industrial, o sistema capitalista passa a submeter tudo ao processo de mercantilização. Essa expansão tem duas dimensões distintas: de um lado temos a expansão espacial, sob o signo da colonização em que novos espaços são submetidos militarmente e depois inseridos na lógica de uma economia mercantilizada; por outro lado tem se uma expansão qualitativa em que mais e mais esferas da vida social passam a fazer parte do mundo das mercadorias. A mercantilização da arte, descrita por Harvey (2005) é um excelente exemplo desse fato.

20 Como uma estrutura de controle absoluto e totalizante o capitalismo não pode se submeter a nenhum tipo de controle, aí temos a grande contradição do capitalismo ser um sistema altamente racionalizado, com unidades básicas buscando o máximo de eficiência baseado em escolhas racionais, sendo ao mesmo tempo um sistema que na escala do próprio sistema é incontrolável e portanto irracional. Por isso cada unidade do capital precisa se adaptar as exigências do sistema, para poder permanecer na 
função de capital, uma vez que a pressão da concorrência obriga a generalização das práticas. Assim mesmo as mais poderosas corporações transnacionais não são capazes de mudar o sentido ou mesmo o ritmo das tendências básicas de desenvolvimento capitalista, apenas podem se adaptar a elas na esperança de continuar existindo enquanto personificação do capital.

21 Em relação a natureza vejamos um exemplo hipotético que pode ser bastante elucidativo do caráter incontrolável do sistema capitalista. Uma empresa transnacional do setor químico tem um processo de produção altamente poluente, sendo que alterar esse processo para torná-lo menos poluente implicaria em um grande investimento, o que levaria a uma ampliação dos seus custos de produção. Ocorre que essa empresa não é a única no seu setor e ela compete no mercado internacional com outras seis empresas do mesmo ramo produtivo. Então se essa empresa resolvesse adotar um processo de produção menos poluente enquanto seus concorrentes não o fazem isso implicaria em aumento de custos para essa empresa. Como o preço dos produtos é uma média social ela não teria como repassar aos preços esse aumento do custo produtivo $\mathrm{e}$ teria então uma redução da margem de lucro que poderia levar a sua falência. Isso significa que essa empresa jamais tomará a decisão de mudar seu processo produtivo. $\mathrm{E}$ caso a legislação do país de origem dessa empresa mude e passe a exigir um processo produtivo menos poluente, a resposta da empresa provavelmente será a transferência de suas plantas produtivas para países em que ela possa continuar poluindo em paz.

22 Este exemplo hipotético aponta para a condição incontrolável da relação entre o capitalismo e a natureza. Por mais que os empresários tenham "consciência ambiental" a sua condição enquanto personificação do capital depende fundamentalmente da externalização de todos os custos relacionados à degradação ambiental decorrente das atividades econômicas. O capital necessita transferir esse custo para a sociedade através do Estado, como forma de viabilizar os lucros privados. Como dissemos isso não depende da consciência ou ética do empresário, mas é uma necessidade que decorre da concorrência capitalista e da busca incessante e infindável por maior lucratividade.

23 Assim a degradação ambiental provocada pelo capitalismo não está ligada a qualquer falta de ética ou de consciência ambiental por parte dos capitalistas ou dos agentes dos governos, mas decorre da incontrolabilidade do sistema do capital e da necessidade que os capitalistas têm de se adaptar aos ditames do sistema, ditados principalmente pela concorrência e que implica, em relação à natureza, na necessidade constante de externalizar os custos ambientais para a sociedade sendo que estes custos acabam normalmente sendo assumidos pelo Estado e não pelo capital. No próximo tópico discutiremos como esses elementos teóricos para se pensar a relação sociedade e natureza favorecem a compreensão do processo de urbanização de Macaé.

\section{A urbanização de macaé e a natureza: um encontro brutal.}

24 A cidade de Macaé se localiza no interior do Estado do Rio de Janeiro, sendo conhecida como a cidade do Petróleo, tendo passado por uma fase de intenso crescimento urbano a partir da década de 1970, devido à implantação da base logística da Petrobras para apoio as atividades offshore na bacia de Campos. A instalação de inúmeras empresas do ramo offshore na cidade, o crescimento da exploração de petróleo na Bacia de Campos e a geração de empregos qualificados e bem remunerados no setor gerou uma intensa 
dinâmica urbana manifestada na expansão constante do tecido urbano e da população que mais que triplicou entre 1970 e 2010 (SILVA, 2019).

Dentro desse contexto, um dos setores com mais intenso dinamismo é justamente o setor imobiliário, em que temos a produção em sequência de bairros nobres, a partir de um eixo que se configura a partir da praia dos Cavaleiros e dentro desses bairros temos a produção de condomínios fechados e outras formas de enclaves como shopping centers. Dentro desse eixo sul, que se inicia grosso modo a partir do bairro de Cavaleiros é que se concentra a produção imobiliária de alto padrão voltada para a classe média e média alta. Outros dois eixos se configuram com a expansão da mancha urbana da cidade a partir da década de 1970: um eixo norte, que se inicia após a ponte da Barra que cruza o Rio Macaé e um eixo oeste que se inicia no bairro Aroeira. 0 mapa 1 apresenta a localização da cidade de Macaé no estado do Rio de Janeiro e dos eixos de expansão urbana dentro dessa cidade.

Mapa 1: localização da cidade de Macaé e seus eixos de expansão urbana.

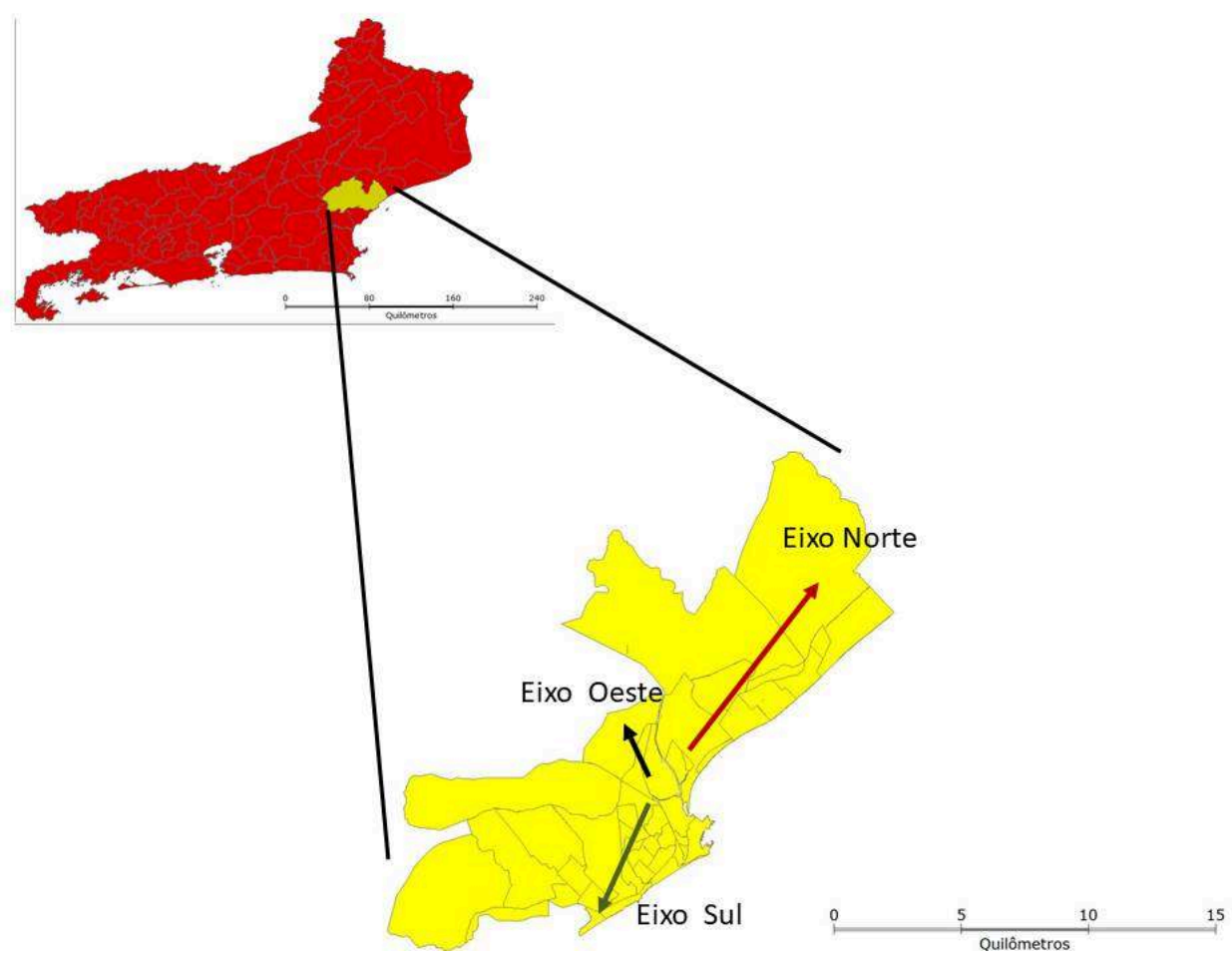

Esse crescimento foi desde o início orientado pela instalação das bases mais importantes da Petrobras na cidade: a base de Imbetiba, o Terminal Cabiúnas e o Terminal Parque de Tubos. Duas dessas unidades foram instaladas em pontos extremos do município, em áreas bem distantes do tecido urbano consolidado da cidade. 0 mapa 2 apresenta a localização dessas bases da Petrobras na cidade: 
Mapa 2: Localização das bases da Petrobras em Macaé.

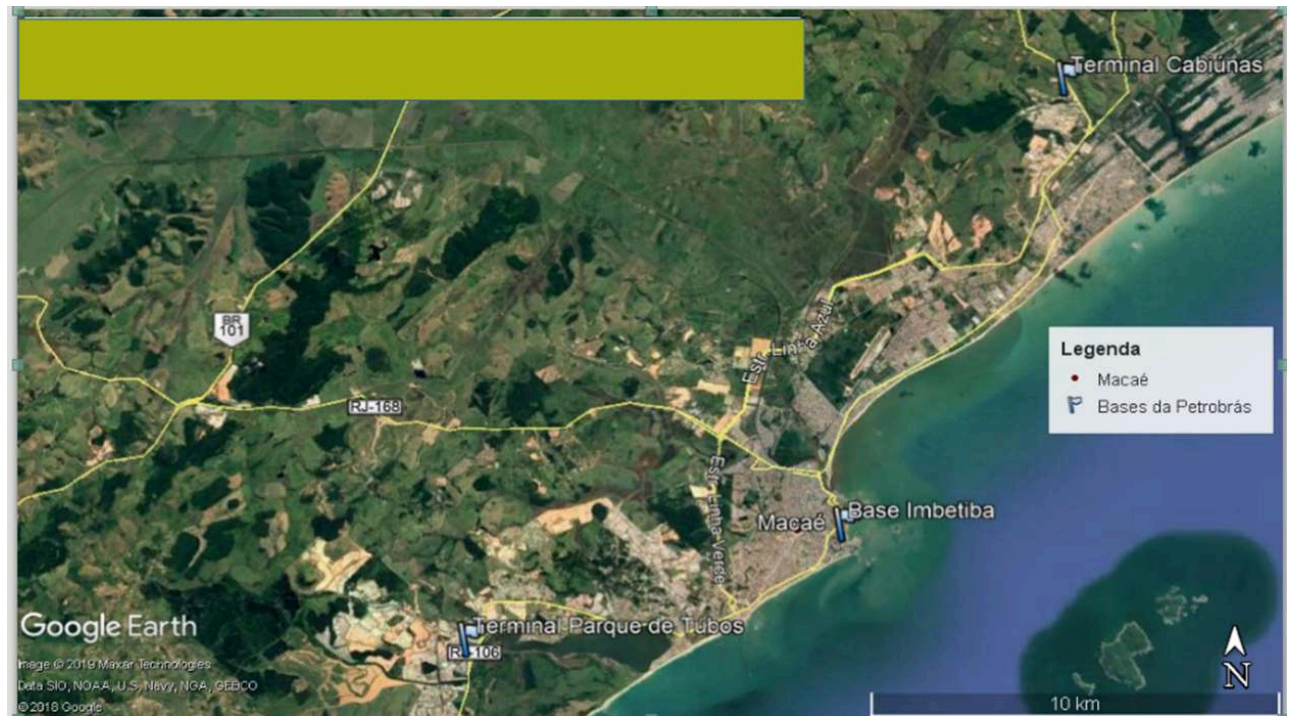

Fonte: Google Earth, elaborado pelo autor.

28 Se compararmos o mapa 2 com o mapa 1, podemos perceber que dos três eixos de expansão mencionados no mapa 1 , dois estão diretamente ligados a presença de instalações da Petrobras. $\mathrm{O}$ eixo Norte está diretamente ligado à presença do Terminal Cabiúnas, instalação da Petrobras utilizada para envio de petróleo e gás para a Reduc e mais recentemente também utilizada como local de beneficiamento do gás natural (Pessanha, 2017). Já o eixo Sul está diretamente ligado à presença do Terminal Parque de Tubos, unidade que funciona como retroporto do porto de Imbetiba, além de abrigar outras instalações da empresa. Na base Imbetiba, por outro lado, além de termos o porto que é utilizado para abastecer as plataformas da bacia de Campos, também temos a base administrativa da empresa na cidade.

29 A base de Imbetiba fica no bairro de mesmo nome, bairro este que é um dos mais antigos da cidade tendo sido este bairro e a praia nele localizado o responsável pela fama de balneário adquirida pela cidade nos anos 1950. Porém o Terminal Parque de Tubos e o Terminal Cabiúnas foram quando da chegada da Petrobras na cidade na década de 1970, localizados em pontos extremos dos limites municipais, sendo o Parque de Tubos bem próximo à divisa com o município de Rio das Ostras e o Terminal Cabiúnas bem próximo à divisa com o município de Quissamã.

30 Nesse momento a malha urbana da cidade correspondia basicamente ao centro da cidade e ao bairro Imbetiba, sendo que no entorno dessas duas instalações praticamente nenhuma ocupação urbana existia. As instalações do Terminal Parque de Tubos e do Terminal Cabiúnas incentivaram não apenas a ocupação no entorno dessas unidades, seja com instalação de empresas offshore seja com o surgimento de loteamentos regulares ou mesmo clandestinos, mas também a ocupação das amplas áreas entre essas unidades e área central da cidade de Macaé. O crescimento da cidade de Macaé, de caráter fortemente linear, também deve ser compreendido no contexto da integração com o município vizinho de Rio das Ostras, sendo que devido a proximidade deste município com o Parque de Tubos e o menor custo dos terrenos fez com que boa parte da expansão urbana que poderia ter se dado em Macaé acabasse se direcionando a este último município, o que reduziu a tensão no sentido da verticalização da cidade. A 
partir disso podemos afirmar a expansão urbana da cidade de Macaé é na sua gênese dispersa, estimulada pela presença dessas duas unidades da Petrobras e do conjunto de empresas que irá se instalar no entorno dessas duas unidades em áreas muito distantes do tecido urbano consolidado da cidade.

31 Tal padrão de expansão urbana, com o tecido urbano se expandindo fortemente nessas duas direções explica algumas características marcantes da estrutura urbana da cidade de Macaé, como a baixa presença de áreas verticalizadas e a extensão fortemente linear da maior parte de sua mancha urbana. Em conjunto com essa grande expansão urbana temos um forte incremente populacional, sendo que segundo dados censitários, o município de Macaé possuía em 1970, 65.318 residentes enquanto em 2000, tinha 132.461 residentes e em 2010, 206.728 residentes. Portanto entre 1970 e 2000 a população do município mais que dobrou enquanto entre 2000 e 2010, portanto ao longo de apenas 10 anos, a população do município cresceu em mais 70.000 habitantes.

Todo esse crescimento representou um encontro brutal entre a natureza e a urbanização, que representou um grau de devastação ambiental assustador. Do ponto de vista geológico o sítio no qual se desenvolve a cidade de Macaé é marcado pela presença de áreas de várzea do rio Macaé e seus afluentes, formadas originalmente por pântanos e extensos manguezais. 0 centro da cidade foi estabelecido em uma área de tabuleiro costeiro menos sujeita a alagamentos, sendo os dois marcos da ocupação da cidade: o forte Marechal Hermes e a Igreja de Santana, localizados em maciços antigos. O mapa 3 mostra a hipsometria do município de Macaé e permite compreender as características gerais do sítio da cidade aqui discutidos.

Mapa 3: hipsometria do município de Macaé.

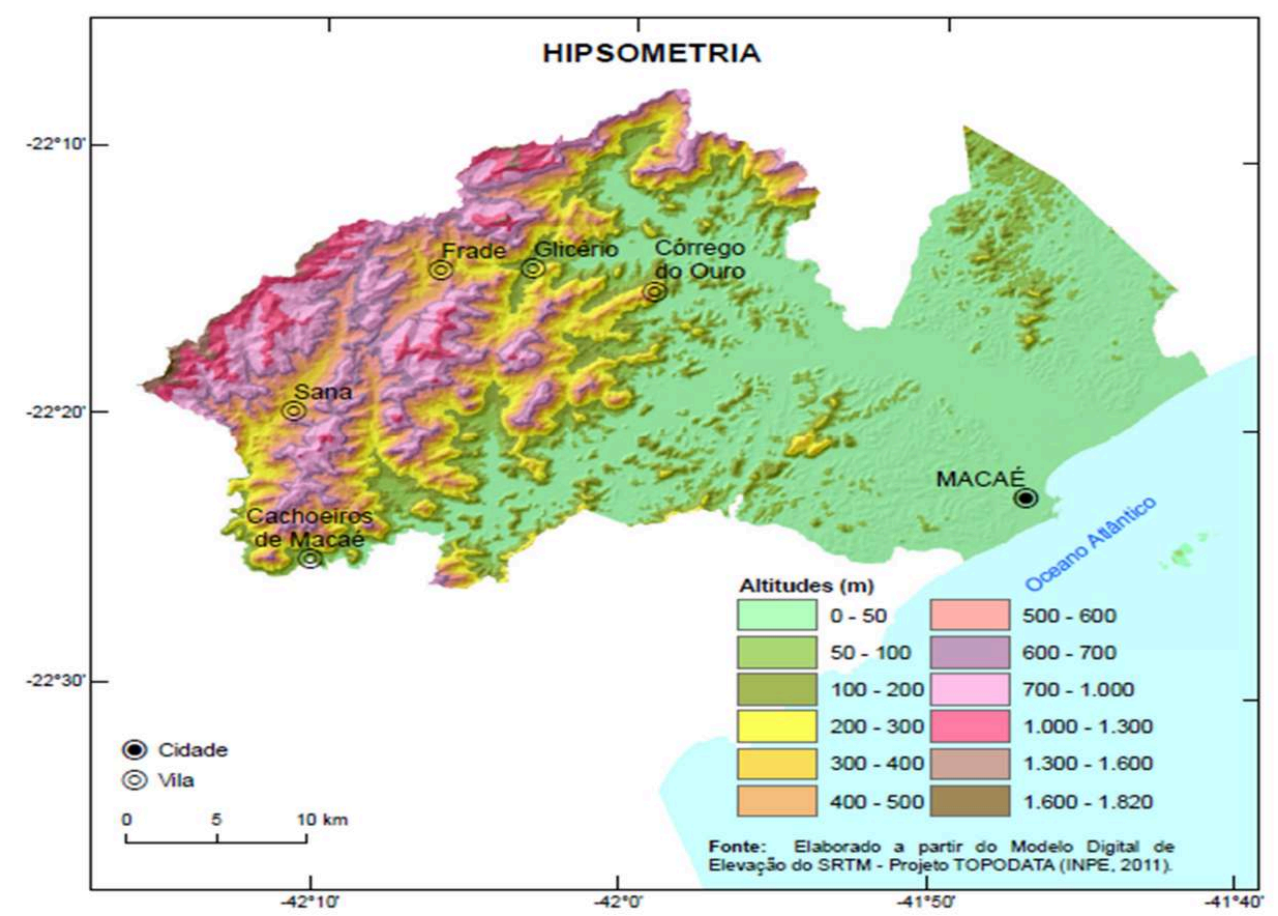

Fonte: http://rigeo.cprm.gov.br/xmlui/handle/doc/18186?show=full, acessado em 02/04/20. Adaptado pelo autor.

Como podemos notar pela análise do mapa, em termos de altitude, a cidade de Macaé apresenta duas unidades completamente distintas: a região serrana, que é parte da 
Serra do Mar e que apresenta altitudes em alguns casos superiores a 1000 metros e uma extensa planície fluvial formada pela sedimentação do Rio Macaé e de seus afluentes e caracterizada pelas baixas latitudes, estando as áreas normalmente no nível do mar. Esta extensa planície fluvial é entrecortada pela presença de alguns maciços antigos como aquele que corresponde ao morro de Santana, onde fica a Igreja de mesmo nome, primeira edificação construída na cidade.

34 Essas extensas planícies tinham, do ponto de vista geomorfológico, uma função muito precisa: as águas das chuvas nas vertentes da Serra do Mar, eram carreadas para essa planície em que temos uma acentuada ruptura de declive, ou seja, passamos de altitudes acima de 1000 metros para terrenos no nível ou abaixo do nível do mar. A consequência dessa abrupta ruptura de declive era uma redução acelerada velocidade do fluxo de água, com formação de canais meândricos e ocupação das planícies fluviais não apenas em momentos de cheia, mas ao longo de praticamente todo o ano, formando terrenos pantanosos, que eram facilmente encontrados em toda essa área de planície fluvial.

Essas planícies eram, portanto, um enorme reservatório, que acumulava água por semanas após episódios de chuva até que as águas pudessem ser escoadas. Ocorre que a imensa expansão urbana que temos na cidade a partir da década de 1970 vai acontecer justamente nestas planícies fluviais, a partir do aterramento de terrenos alagadiços e pantanosos, além das extensas áreas de mangue encontradas na foz do rio Macaé. Tal expansão urbana causou um enorme desequilibro dos ecossistemas com o desaparecimento de aves e outros animais que habitavam os terrenos pantanosos, que foram aterrados e drenados para a expansão urbana. Por outro lado, ao eliminar as áreas na qual as águas das chuvas eram armazenadas durante o período de chuvas esse crescimento urbano tornou onipresente o problema dos alagamentos, que se dá em vários pontos da cidade, em especial nos bairros novos que surgiram a partir da ocupação das áreas da planície fluvial ou dos manguezais. Boa parte dessa expansão urbana se dá pela produção de bairros populares, produzidos no formato de loteamentos populares ou mesmo como ocupações. 0 mapa 4 apresenta uma imagem com parte da área urbanizada de Macaé.

Mapa 4: imagem da cidade de Macaé com destaque para BR 101, Linha Azul e Linha Verde .

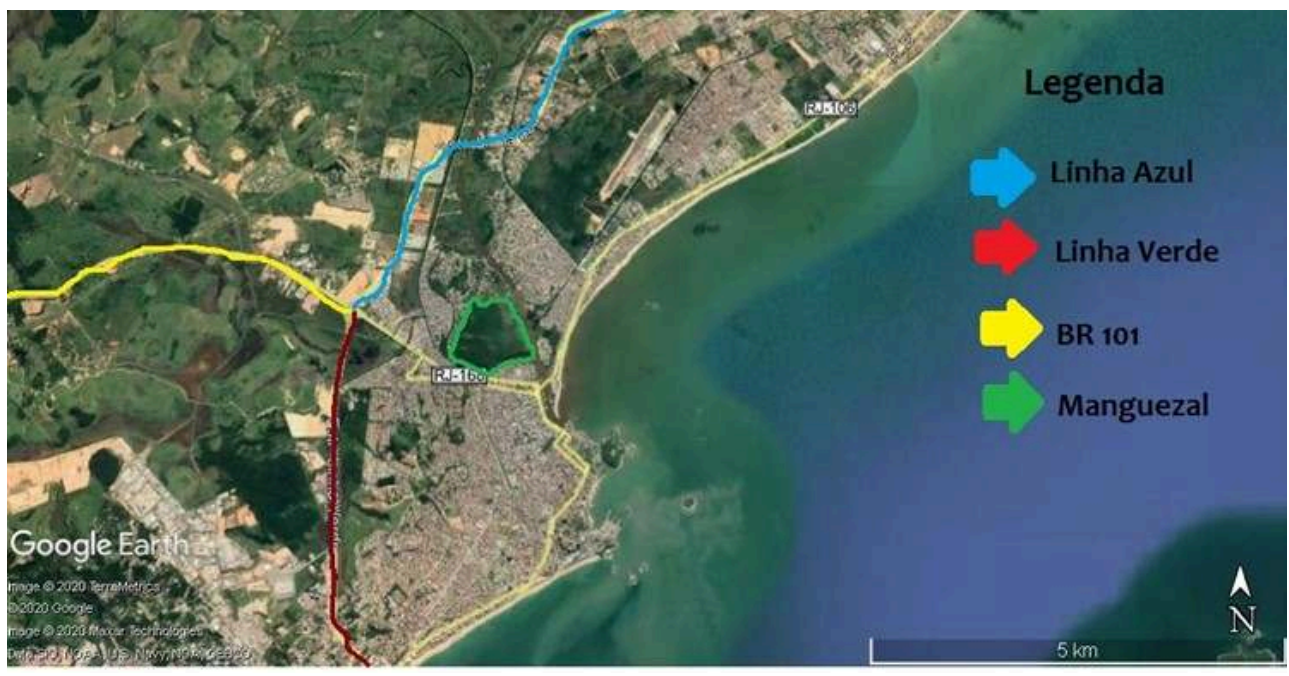

Fonte: Google Earth, adaptado pelo autor. 
36 Na imagem aparecem em destaque 3 estradas fundamentais para o funcionamento da logística de transporte da cidade. A BR 101 faz a ligação de Macaé com a cidade do Rio de Janeiro enquanto as estradas municipais Linha Verde e Linha Azul começam iniciam no mesmo lugar, no entroncamento com a BR 101 e se destinam aos pontos extremos da cidade: a Linha Verde permite a ligação entre a BR 101 e o terminal Parque de Tubos enquanto a Linha Azul permite a ligação entre a BR 101 e o Terminal Cabiúnas. Do ponto de vista logístico a construção da linha verde nos anos 1990 e da linha azul nos anos 2000 representou um grande desafogamento do trânsito no centro da cidade. Antes da criação dessas duas vias as enormes carretas que vinham com peças do Rio de Janeiro ou de São Paulo com destino ao Parque de Tubos ou ao Terminal Cabiúnas eram obrigadas a passar pelo centro da cidade. A passagem das carretas, com comprimento muitas vezes superior a 20 metros pelo centro da cidade, com suas ruas estreitas, causava enorme transtorno, gerando engarrafamento e problemas constantes como a ruptura de fios de alta-tensão.

37 Com a criação dessas duas estradas todo o tráfego de veículos pesados foi retirado do centro da cidade sendo que essas carretas agora acessam o Terminal Parque de Tubos pela Linha Verde e o terminal Cabiúna pela Linha Azul. Portanto, do ponto de vista da logística de transporte a construção dessas duas estradas municipais foi um grande acerto uma vez que levou ao descongestionamento do centro da cidade. Do ponto de vista ambiental, no entanto, a construção das estradas consolidou o desastre que já vinha se desenhando desde a década de 1970 em Macaé: ao aumentar a acessibilidade de áreas até então praticamente inacessíveis, a construção dessas duas estradas criou novos focos de valorização imobiliária e permitiu a expansão urbana ao longo das duas estradas sendo que em ambas as estradas as áreas do seu entorno constituíam anteriormente áreas pantanosas que foram drenadas e aterradas para produ imobiliária.

38 O polígono destacado na cor verde na imagem corresponde a basicamente ao último remanescente de manguezal ainda em pé diante do intenso processo de expansão urbana da cidade, sendo que a construção da Linha Azul contribui bastante para a ocupação dessa antes extensa área de manguezal que vem sendo sistematicamente reduzida desde a construção desde antes da construção dessa estrada. Sua construção, porém incentivou o processo de fusão entre os eixos Oeste e Norte mostrados no mapa 1. O eixo Oeste começa a partir da ocupação do bairro Aroeira contíguo ao centro da cidade, enquanto o eixo Norte se inicia a partir da ocupação do bairro Barra de Macaé, bairro também contíguo ao centro da cidade porém dele separado pela foz do Rio Macaé (que aparece como uma linha marrom na imagem). Embora ambos os eixos tenham uma característica predominante de ocupação por áreas residenciais populares, ambos tinham um desenvolvimento independente até a década de 1990.

39 (BARUQUI, 2004) aponta que a partir das favelas da Malvinas (eixo oeste) e Nova Holanda (eixo sul) houve uma acelerada ocupação das áreas pantanosas existentes entre essas duas favelas. Essa ocupação se deu inicialmente em torno de uma área de preservação ambiental existente entre esses dois bairros denominada Colônia Leocádia. A ocupação dessa área eliminou a separação física entre os eixos Norte e Oeste colocando-os como um único eixo de expansão de bairros de caráter popular e características infraestruturais precárias. Esse crescimento se dá pela ocupação via aterramento de áreas componentes da planície fluvial sejam elas pantanosas ou não. A consequência é tanto a expansão de bairros precários, afetados por todo tipo de déficit 
de infraestrutura, falta de acessibilidade, de esgotamento sanitário e mesmo em alguns casos, de água, como o agravamento do problema das enchentes. Importante anotar que essa expansão urbana não se dá apenas a partir da produção de bairros populares ilegais do ponto de vista jurídico e urbanístico, pois ao longo da Linha Azul existem diversos condomínios fechados, conjuntos habitacionais e loteamentos que foram devidamente aprovados junto à prefeitura. As imagens na figura 1, 2 e 3 mostram um pouco dos contrastes relacionados ao crescimento urbano nos eixos Norte e Oeste da cidade:

Figuras 1, 2 e 3: Bairro Nova Holanda, Malvinas e condomínio fechado na Linha Azul.
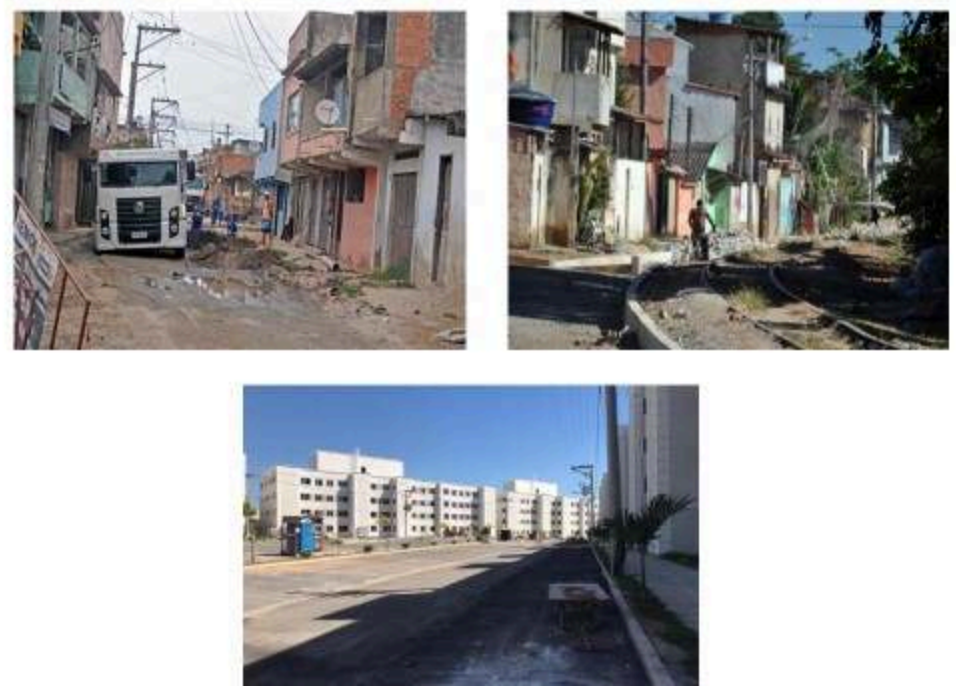

Fonte: arquivo do autor.

As imagens mostram na sequência da esquerda para a direita os bairros da Nova Holanda, Malvinas e o condomínio fechado Parque Maracaibo, construído pela MRV na Linha Azul. o bairro de Nova Holanda se localiza no eixo Norte, logo após a Barra de Macaé, bairro no qual houve o início da expansão em direção a esse eixo. Segundo (BARUQUI, 2004) o bairro Nova Holanda, surge a partir da ocupação irregular de glebas que pertenciam ao INCRA e que não tinham recebido nenhuma destinação. Por outro lado o bairro Malvinas também foi resultado de uma ocupação irregular, desta vez em terrenos da Marinha, de acordo com a autora citada acima. Ambos os bairros são considerados favelas, por apresentarem acentuado déficit infraestrutural, em termos de condições de saneamento básico, acessibilidade ou acesso à cultura e ao lazer. Por outro lado a terceira imagem mostra um condomínio fechado localizado na Linha Azul pela construtora MRV que apresenta um grande constaste em termos infraestruturais em comparação com esses dois bairros embora também tenha sido construído em área sujeita a alagamento.

41 Com base nessa exposição sobre as características ambientais da urbanização macaense podemos retomar os argumentos teóricos da primeira parte do trabalho para discutir esse processo de urbanização. A terra como mercadoria fictícia aparece claramente como um elemento para pensar o processo de urbanização em Macaé, já que boa parte da terra urbana simplesmente não existia antes da transformação em terra urbana. Eram áreas pantanosas e de manguezal, que não correspondiam a áreas já com uso 
econômico. Não se trata, portanto, de áreas rurais convertidas ao uso urbano, no qual temos apenas uma mudança da função da terra. Neste caso o fato de ter havido uma conversão de um tipo de uso para outro pode ofuscar a realidade da terra se tratar de uma mercadoria fictícia como aponta Polanyi (2012). Mas no caso da cidade de Macaé, boa parte daquilo que constitui sua área urbana hoje eram terras sem nenhum tipo de uso econômico, identificadas diretamente como natureza, o que salienta ainda mais o caráter fictício da terra como mercadoria.

42 A simples operação de aterramento e delimitação de lotes e ruas é o suficiente para converter uma área pantanosa, um manguezal, ou uma grande gleba qualquer sem uso, em terra urbana, uma mercadoria a ser comprada no mercado. Na verdade a operação de loteamento pode ocorrer ainda antes do aterramento, sendo que o autor testemunhou in loco o parcelamento da ocupação Nova Leocádia quando da produção desse bairro popular. Especialmente marcado na minha memória foi ver o pântano porque passava todas as semanas já todo demarcado por cordas e pedaços de madeira, antes mesmo do aterramento, e um dos lotes já com o preço de venda. Tratava-se apenas, na minha visão de adolescente, de um pedaço de terreno alagado e fétido e não conseguia compreender como alguém poderia pagar algo por aquilo. Mas em cerca de duas semanas o imenso terreno pantanoso já estava aterrado, com casas construídas, e mesmo presença de bares, mercados, lojas de materiais de construção e igrejas.

43 O meu espanto diante do surgimento daquele novo bairro irregular e especialmente do lote a venda reflete justamente a compreensão intuitiva do caráter fictício da mercadoria terra, pois aqui se trata justamente disso de transformar em mercadoria algo que há poucas semanas era apenas uma área pantanosa de uso comum e propriedade jurídica desconhecida. Assim quando vemos uma imensa área antes identificada diretamente como natureza, ser convertida, em poucas semanas, por uma ação coordenada e convergente, num mosaico de mercadorias apropriadas privadamente, temos a constatação evidente do caráter fictício da mercadoria terra.

44 Por outro lado o processo rápido de urbanização de Macaé pode ser considerado uma forma extrema de submeter à natureza a um brutal processo de tortura, para converter espaços naturais em espaços urbanizados, privatizados e mercantilizados. Como aponta Hinkelammert (2007) à relação entre o capital e natureza sempre se dá na forma da lógica da tortura, ou seja, a busca pela máxima eficiência na conversão da natureza em produtos lucrativos, independente dos resultados mais amplos desses processos produtivos. Se considerarmos a urbanização macaense, tanto a operada por empresas do mercado imobiliário e seguindo padrões jurídicos e urbanísticos tanto a ilegal, podemos concluir que esta pode ser vista como a produção de uma enorme massa de mercadorias composta pelos terrenos ou casas colocados a venda após o processo produtivo.

45 Ocorre que na maioria dos casos essa produção colossal de mercadorias: na produção das parcelas urbanas se utilizam áreas naturais como matérias-primas, sendo que essas áreas naturais são violentamente torturadas, sendo desmatadas, aterradas e posteriormente parceladas para venda independente da existência de infraestrutura urbana. Importante afirmar que essa lógica de torturar a natureza, convertendo áreas naturais em terra urbana, está presente tanto nas áreas produzidas pelos promotores imobiliários, quanto nas áreas de ocupação em que os terrenos são vendidos de forma independente da realidade de que quem vende não possui de fato a titularidade da terra. Como consequência desse processo de urbanização, que é ao mesmo tempo um 
processo de torturar a natureza para convertê-la em mercadoria temos no município de Macaé atualmente 14 espécies ameaçadas de extinção, afetadas diretamente pelas consequências dessa urbanização acelerada (O DEBATE, 2012).

46 A urbanização em Macaé também exemplifica de forma clara a incontrolabilidade do sistema do capital em seu desenvolvimento. Por mais que em algumas sociedades o processo de urbanização tenha como característica ser em parte passível de controle pelo poder público, isto se dá em principalmente pelo fato de serem sociedades cujos estados estão no núcleo orgânico do capitalismo, o que significa que eles dispõem de mais amplos recursos oriundos em grande parte da exploração de recursos baratos de países mais pobres (ARRIGUI, 1997) e também de uma sociedade civil melhor organizada e com maior capacidade de exigir investimentos do poder público.

47 Mas mesmo em países desenvolvidos a incontrolabilidade está fortemente presente no processo de urbanização, no sentido de que a maior parte dos investimentos e dos esforços do poder público estão direcionados para fomentar a acumulação de capital no urbano e pelo urbano e não para o atendimento das demandas sociais e ambientais. Isto se viu, por exemplo, após a crise de 2008 , quando o governo americano se apressou a ajudar financeiramente os bancos, os mesmos bancos que estavam executando hipotecas e colocando milhares de moradores nas ruas, moradores estes que não tiveram praticamente nenhuma assistência do governo (HARVEY, 2011). Mesmo na cidade mais rica dos EUA, o governo local prefere gastar dinheiro exportando seus moradores de rua para lugares distantes do que investindo em moradia popular (El PAIS BRASIL, 2019).

48 Em Macaé a incontrolabilidade aparece de forma ainda mais evidente e mesmo brutal, uma vez que boa parte da área urbana de Macaé foi produzida na mais completa ilegalidade, tanto do ponto de vista jurídico quanto urbanístico, sem que o executivo municipal atuasse no sentido de conter ou modificar a forma ambientalmente devastadora como a cidade estava sendo produzida. Isto ocorria em grande parte, é preciso dizer, porque o executivo municipal estava preocupado em dotar de infraestrutura os espaços almejados pelo capital imobiliário e assim sendo fazia vista grossa ao desenvolvimento da cidade ilegal, isso além da falta de recursos e de pessoal técnico qualificado para regular a expansão urbana da cidade.

49 Além disso, esse processo de expansão, que muitas vezes desrespeita as normas urbanísticas e ambientais, também está relacionado a interesses econômicos presentes na esfera de poder municipal. Um caso bastante conhecido na cidade é de um vereador da cidade que vendeu a Prefeitura uma série de terrenos na linha verde em que foi construída uma estação de tratamento de esgotos além da nova sede da Câmara e do Fórum da cidade. Tais obras assim como a própria construção da linha verde atuaram no sentido de valorizar outros terrenos desse vereador, que é também um grande proprietário fundiário dessa área.

50 Assim podemos ver como a urbanização macaense exemplifica e clarifica a discussão sobre a natureza como uma mercadoria fictícia, convertida em mercadoria sob a lógica da tortura, e dentro de um processo de urbanização incontrolável, uma vez que sujeito aos interesses despóticos do capital, que sempre prevalecem, diante de outras necessidades socialmente ou ambientalmente mais relevantes. Dessa maneira pudemos compreender como esses três aspectos da relação entre a sociedade capitalista, discutidos nesse texto estão entrelaçados e favorecem a compreensão da urbanização veloz e brutal da cidade de Macaé. 


\section{CONSIDERAÇÕES FINAIS.}

51 Nesse trabalho apresentamos três formulações teóricas distintas que auxiliam na compreensão da relação entre a natureza e o capital. Tomando como exemplo o processo de urbanização de Macaé, podemos discutir como essas formulações teóricas são complementares, ou seja, o desenvolvimento capitalista, em relação a natureza se baseia na conversão da terra em mercadoria, esse processo de conversão é regido pela lógica da tortura e tem como consequência um processo de desenvolvimento que é em grande parte incontrolável. Assim da compreensão da relação do capital com a natureza surge a questão: o que fazer? Trata-se de uma relação destrutiva, incontrolável e não há nada que possa ser feito por aqueles conscientes da necessidade da preservação do meio ambiente a não ser lutar por uma radical transformação social que pode não vir a tempo de nos salvar da tragédia ambiental que se anuncia?

52 Acreditamos que a incontrolabilidade da relação entre o capital e a natureza, especialmente em relação ao processo de urbanização opera dentro de limites. Se existem alguns limites que são intransponíveis em relação a essa incontrolabilidade, existem outros dentro dos quais é possível se trabalhar dentro da perspectiva de um planejamento urbano crítico (SOUZA, 2006). Em outras palavras, admitimos que a urbanização macaense não precisava ter sido a tragédia que foi, se houvesse uma sociedade civil mais organizada e um governo com mais capacidade técnica e um projeto de futuro para cidade que incluísse investimentos pesados em moradia popular. E se o passado da urbanização macaense, não precisava ser toda essa tragédia que foi acreditamos que o futuro dessa urbanização também possa ser diferente em grande parte mitigando os efeitos desastrosos da urbanização passada e resgatando um pouco da dívida social e ambiental associada a esse padrão de urbanização.

\section{BIBLIOGRAFIA}

ARRIGUI, Giovani. A ilusão do desenvolvimento. Petrópolis: Vozes, 1997.

BARUQUI, Solange Silva Carvalho. A cidade formal e a cidade informal em macaé: uma análise do crescimento habitacional na década de 90. Campos dos Goytacazes, Dissertação de Mestrado em Planejamento Regional e Gestão de Cidades. Programa de Pós-Graduação em Planejamento Regional e Gestão de cidades, Universidade Cândido Mendes, 2004.

EL PAÍS BRASIL. Nova York gasta 89 milhões de dólares para 'exportar' sem-teto para o resto dos EUA, 2019. Disponível em:

https://brasil.elpais.com/brasil/2019/11/06/internacional/1573059962_996748.html. Acessado em 11/04/2020.

G1/GLOBO. Hydro Alunorte anuncia suspensão de 100\% das atividades em Barcarena e Paragominas,2018. 
Disponível em:https://g1.globo.com/pa/para/noticia/2018/10/03/alunorte-anuncia-suspensaode-100-das-atividades-em-barcarena-e-paragominas-no-para.ghtml. Acessado em 04/01/2020.

HARVEY, David. A produção capitalista do espaço. São Paulo: Ana Blume. 2005.

HARVEY, David. O enigma do capital e as crises do capitalismo. São Paulo: Boitempo, 2011.

HINKELLAMERT, Franz. A globalidade da terra e a estratégia da globalização. In: Atilio Boron (org.). A teoria marxista hoje: problemas e perspectivas. Buenos Aires: Clacso, 2007.

MARX, Karl. O capital: crítica da economia política, livro I: o processo de produção do capital. Rio de Janeiro: Civilização Brasileira, 2011.

MESZÁROS, Itsván. Para além do capital: rumo a uma teoria da transição. São Paulo: Boitempo, 2011.

O DEBATE. Macaé abriga espécies ameaçadas de extinção, 2012. Disponível em: https:// www.odebateon.com.br/site/noticia/detalhe/25832/macae-abriga-especies-ameacadas-deextincao. Acessado em 10/04/2020.

PAGANOTO, F. Mobilidade e trabalho em Macaé-RJ, a capital do petróleo. Rio de Janeiro, Dissertação de Mestrado em Geografia. Programa de Pós-Graduação em Geografia, Universidade Federal do Rio de Janeiro, 2008.

PESSANHA, Roberto Moraes. Relação transescalar e multidimensional "Petróleo-Porto" como produtora de novas territorialidades. Rio de Janeiro: Tese de doutorado em Políticas Públicas e Formação Humana. Programa de Pós-Graduação em Políticas Públicas e Formação Humana, Universidade do Estado do Rio de Janeiro, 2017.

POLANYI, Karl. A grande transformação: as origens da nossa época. Rio de Janeiro: Elsevier, 2012.

SILVA, Oséias Teixeira da. O processo de integração urbana em discussão: o papel dos deslocamentos pendulares na conformação de uma aglomeração urbana não-metropolitana. Revista Espaço e Economia, Vol. 8, n016, 2019.

SOUZA, Marcelo Lopes de. A prisão e a Ágora: reflexões em torno da democratização do planejamento e da gestão das cidades. Rio de Janeiro: Bertrand Brasil, 2006.

\section{RESUMOS}

A ascensão do capitalismo como sistema a regular as relações metabólicas da sociedade e da natureza impõem intensas transformações ao meio ambiente. 0 presente trabalho buscará trazer elementos para a compreensão dessa questão a partir da discussão teórica e também de um trabalho empírico sobre as transformações ambientais advindas da urbanização na cidade de Macaé - RJ. Discutimos as conseqüências da transformação da terra em mercadoria com base no trabalho de Karl Polanyi, a lógica da tortura como forma de relação com a natureza com base em Franz Hinkelammert, e a incontrolabilidade do sistema do capital e sua relação com degradação ambiental com base em Itsván Mészáros. A partir desses elementos teóricos discutimos a urbanização de Macaé como um encontro brutal entre a natureza e o capitalismo, marcado pela mercantilização da terra, pela tortura dos espaços naturais e pela incontrolabilidade da urbanização com um todo.

The rise of capitalism as a system to regulate the metabolic relations of society and nature impose intense changes to the environment. The present work will seek to bring elements for the understanding of this issue from the theoretical discussion and also from an empirical work on 
the environmental transformations arising from urbanization in the city of Macaé - RJ. We discussed the consequences of transforming the land into a commodity based on the work of Karl Polany, the logic of torture as a form of relationship with nature based on Franz Hinkelammert, and the uncontrollability of the capital system and its relationship with environmental degradation based on in Itsvan Mezaros. Based on these theoretical elements, we discussed urbanization of Macaé as a brutal encounter between nature and capitalism, marked by the commodification of the land, the torture of natural spaces and the uncontrollability of urbanization as a whole.

La montée du capitalisme en tant que système de régulation des relations métaboliques de la société et de la nature impose des changements intenses à l'environnement. Le présent travail cherchera à apporter des éléments de compréhension de cette question à partir de la discussion théorique et aussi d'un travail empirique sur les transformations environnementales découlant de l'urbanisation de la ville de Macaé-RJ. Nous avons discuté des conséquences de la transformation de la terre en une marchandise basée sur le travail de Karl Polanyi, de la logique de la torture comme forme de rapport à la nature basée sur Franz Hinkelammert, et de l'incontrôlabilité du système capital et de sa relation avec la dégradation environnementale basée sur à Itsván Meszáros. Sur la base de ces éléments théoriques, nous avons abordé l'urbanisation de Macaé comme une rencontre brutale entre la nature et le capitalisme, marquée par la marchandisation de la terre, la torture des espaces naturels et l'incontrôlabilité de l'urbanisation dans son ensemble.

El surgimiento del capitalismo como un sistema para regular las relaciones metabólicas de la sociedad y la naturaleza impone cambios intensos al medio ambiente. El presente trabajo buscará aportar elementos para la comprensión de este tema de la discusión teórica y también de un trabajo empírico sobre las transformaciones ambientales que surgen de la urbanización en la ciudad de Macaé - RJ. Discutimos las consecuencias de transformar la tierra en una mercancía basada en el trabajo de Karl Polany, la lógica de la tortura como una forma de relación con la naturaleza basada en Franz Hinkelammert, y la incontrolabilidad del sistema de capital y su relación con la degradación ambiental basada en en Itsvan Mezaros. Sobre la base de estos elementos teóricos, discutimos la urbanización de Macaé como un encuentro brutal entre la naturaleza y el capitalismo, marcado por la mercantilización de la tierra, la tortura de los espacios naturales y la incontrolabilidad de la urbanización en su conjunto.

\section{ÍNDICE}

Palabras claves: Economia, naturaliza, urbanización, Macaé.

Keywords: Economy, nature, urbanization, Macaé

Mots-clés: Économie, nature, urbanisation, Macaé

Palavras-chave: Economia, natureza, urbanizacão, Macaé.

\section{AUTOR}

\section{OSÉIAS TEIXEIRA DA SILVA}

Instituto Federal Fluminense -IFF

Professor EBTT. Email: oseias.silva@iff.edu.br 